\title{
BMJ Open Epidemiological and outcome analysis of COVID-19-associated pneumothorax: multicentre retrospective critical care experience from Qatar
}

\author{
Jaweria Akram (D) , ${ }^{1}$ Zohaib Yousaf (D) , ${ }^{1}$ Yasir Alabbas (D) , ${ }^{1}$ \\ Mustafa Ibrahim Abdullah Almoyaaf, ${ }^{1}$ Abdus Salam Saif Ibrahim, ${ }^{2}$ Nadir Kharma ${ }^{2}$
}

To cite: Akram J, Yousaf Z, Alabbas $Y$, et al. Epidemiological and outcome analysis of COVID19-associated pneumothorax: multicentre retrospective critical care experience from Qatar. BMJ Open 2022;12:e053398. doi:10.1136/ bmjopen-2021-053398

\section{- Prepublication history and} additional supplemental material for this paper are available online. To view these files, please visit the journal online (http://dx.doi.org/10.1136/ bmjopen-2021-053398).

ZY and NK are joint senior authors.

Received 16 May 2021 Accepted 12 January 2022

Check for updates

(c) Author(s) (or their employer(s)) 2022. Re-use permitted under CC BY-NC. No commercial re-use. See rights and permissions. Published by BMJ.

${ }^{1}$ Internal Medicine, Hamad Medical Corporation, Doha, Qatar

${ }^{2}$ Critical Care Medicine, Hamad Medical Corporation, Doha, Qatar

Correspondence to Dr Zohaib Yousaf; zohaib.yousaf@gmail.com

\section{ABSTRACT}

Objectives To study the incidence, characteristics, treatment, associated risk factors and outcome of COVID19-associated pneumothorax in intensive care unit (ICU). Design Retrospective observational data review. Setting A multicentre study from ICUs of three tertiary care hospitals in Qatar.

Participants 1788 patients with COVID-19 pneumonia requiring ICU admission from 1 March 2020 to 1 November 2020 were enrolled in this study.

Interventions Not applicable.

Primary and secondary outcome measures The primary endpoint was to identify the incidence of COVID19-associated pneumothorax in patients requiring ICU admission. Secondary endpoints were to determine the associated risk factors, treatment, mortality and morbidity. Results 1788 patients from 3 centres were reviewed in the study. The total episodes of pneumothorax were 75. Pneumothorax occurred in $4.2 \%$ of the patients with COVID-19 pneumonia requiring ICU admission. The majority of the subjects were male $(n=72,96 \%)$. The mean age was 55.1 ( \pm 12.7 years). The majority of the subjects were nationals of South Asian countries and the Middle East and North Africa regions. 52\% $(n=39)$ of the patients were previously healthy without comorbidities before ICU admission. The recurrence rate was $9.3 \%$. The median length of ICU stay was 28 days (20.5-45.8 days). After developing pneumothorax, the length of mechanical ventilation ranged from 6 to 32 days, with a median of 13 days. $44 \%$ of patients eventually ended up with tracheostomy. In-hospital mortality in the patients with COVID-19-related pneumothorax was 53.3\% $(n=40)$. The odds of mortality in patients with COVID-19 pneumonia with pneumothorax is $7.15(95 \% \mathrm{Cl} 4.45$ to $11.48, p<0.0001$ ) compared with those who did not develop pneumothorax. This indicates pneumothorax is a potential independent risk factor associated with mortality in patients with COVID-19 pneumonia requiring ICU admission.

Conclusions Pneumothorax is a common complication in patients with COVID-19 requiring ICU admission, associated with poor prognosis and outcome. Trial registration number The study was approved by the Medical Research Centre (MRC) Qatar. (MRC-0120-1116)
Strengths and limitations of this study

- This multicentre study provides detailed demographics, risk factors, morbidity and mortality of pneumothorax in critically ill COVID-19 patients.

- Multiple outcome assessments are performed.

- The retrospective, observational nature of the study is the major limitation.

- Data on some variables like smoking could not be extracted from the electronic medical records.

- The absence of data on comparative controls is a limitation.

\section{BACKGROUND}

COVID-19 is caused by the SARS-CoV-2, which can affect multiple organs of the body. ${ }^{1}$ The most commonly involved organ system is the respiratory system. The spectrum of pulmonary complications ranges from alveolar damage leading to pneumonia, acute respiratory distress syndrome (ARDS), or an effect on the coagulation cascade causing pulmonary infarction via thrombi and emboli. ${ }^{2}$

Pneumothorax is one of the known pulmonary complications of COVID-19. The incidence of pneumothorax in COVID-19 is approximately $1 \%$ in patients requiring hospital admission and 2\% in intensive care unit (ICU) admissions. ${ }^{3-6}$ The risk factors predisposing to the development of pneumothorax include advanced age, pre-existing lung disease, and mechanical ventilation. ${ }^{6}$

The underlying pathophysiology is unclear, but cyst formation in the diseased areas of the lungs may be a precipitating factor as the cysts can progress to bullae associated with the development of pneumothorax. ${ }^{6}$ Cyst formation also occurs with barotrauma and is seen as a late consequence of ARDS. ${ }^{7}$ Barotrauma is reported in $15 \%$ of patients with COVID-19 requiring invasive mechanical ventilation. ${ }^{7}$ Barotrauma is considered an 
independent risk factor for death and is associated with a more extended hospital stay in patients with COVID-19. ${ }^{7}$

We have conflicting data regarding the association of pneumothorax with mortality in COVID-19 patients, with older studies reporting that the development of pneumothorax is not an independent marker of poor prognosis. However, evolving evidence is in favour of the association of pneumothorax with high mortality. ${ }^{8-10}$ The mortality rate of COVID-19 patients admitted to ICU is reported up to $39 \% .^{7}$ There is a higher incidence of pneumothorax in critically ill COVID-19 patients with ARDS. This combination of patients with ARDS developing pneumothorax results in a prolonged hospital stay and a high mortality rate of up to $80 \% .{ }^{11}$ Data from the ISARIC4C study concludes that pneumothorax is associated with increased mortality in COVID-19. ${ }^{10}$

We carried out a multicentre retrospective study to establish the incidence of pneumothorax in patients with COVID-19 requiring ICU admission in Qatar. The study also describes the characteristics, treatment, associated risk factors and outcome of COVID-19-associated pneumothorax in Qatar.

\section{STUDY DESIGN AND METHODS}

This is a multicentre, retrospective study. Patients admitted to the ICU of Hamad General Hospital, Hazm Mebaireek General Hospital and Cuban hospital diagnosed with COVID-19-associated pneumothorax between 1 March 2020 and 1 November 2020 were identified from the patient registry and included in this study. Data were gathered retrospectively from the electronic health record system (Cerner.)

\section{Inclusion criteria}

1. All patients 14 years and older were admitted to ICU with a diagnosis of COVID-19 and pneumothorax.

2. Confirmed COVID-19 status by a positive nasopharyngeal/oropharyngeal or tracheal aspirate positive for SARS-CoV-2 reverse transcription-PCR (RT-PCR.)

3. Confirm pneumothorax by at least one imaging modality, including chest X-ray (XR), point of care ultrasound or chest CT scan.

\section{Exclusion criteria}

1. Age less than 14 years old.

2. Indeterminate or negative RT-PCR for SARS-CoV-2.

3. COVID-19 diagnosis based on rapid antigen testing.

4. Any patient with a presumptive diagnosis of COVID-19 based on clinical diagnosis.

5. No clear evidence of pneumothorax on imaging.

6. Patients not admitted to ICU.

\section{Outcomes}

Primary outcome

1. To identify the incidence of pneumothorax in patients with COVID-19 admitted to ICU in Qatar.
Secondary outcome

1. To assess the risk factors associated with the development of pneumothorax in COVID-19 patients.

2. To assess the treatment of the disease.

3. To assess mortality and morbidity associated with developing pneumothorax.

\section{Statistical analyses}

Descriptive and summary statistics were used to describe the study cohort's sociodemographic parameters, with continuous variables presented as means $( \pm \mathrm{SD})$ or median (IQR) as appropriate. Categorical variables were presented as numbers (percentages). The Shapiro-Wilk tests analysed the normality of the data. We used oneway ANOVA (Welch's) for the parametric variables and Kruskal-Wallis for the non-parametric variables for the comparison. All data were analysed using Jamovi V.1.2 (created in 2020, Sydney, Australia).

\section{Patient and public statement}

No patient and public involvement.

This is a retrospective data review, so it was not possible to involve the patients or public in our research's design, conduct or dissemination plans.

\section{RESULTS}

Incidence of pneumothorax in COVID-19 patients admitted to ICU

Our cohort consisted of 1788 patients with COVID-19 requiring ICU admission from 1 March 2020 to 1 November 2020. Seventy-five out of 1788 subjects developed pneumothorax. Three episodes were post-traumatic and were incidentally found to have COVID-19, so they were excluded from the analysis. Pneumothorax occurred in $4.2 \%$ of the patients with COVID-19 pneumonia requiring ICU admission.

\section{Demographic and clinical characteristics}

The majority of the subjects were male $(96 \%)$, with $4 \%$ female. The mean age was 55.1 years $( \pm 12.7$ years $)$. The majority $(72 \%)$ of the subjects were of Southern and Southeast Asian ethnicity. 17.3\% belonged to the Middle East and North Africa (MENA) regions, and 10.7\% belonged to other ethnicities (table 1).

The median height was $168 \mathrm{~cm}(164-170 \mathrm{~cm})$ and the mean body mass index was $27.2 \mathrm{~kg} / \mathrm{m}^{2}( \pm 3.9 \mathrm{~kg} / \mathrm{m} 2)$. The majority $(52 \%, \mathrm{n}=39)$ of the patients had no comorbidity before ICU admission. 29.3\% had type 2 diabetes mellitus, another $21 \%$ had hypertension, $4 \%$ had cerebrovascular accident or coronary artery disease. Prior respiratory diseases were found in only $9.3 \%$ of patients. $6.7 \%$ had asthma, $1.3 \%$ had pulmonary tuberculosis and $1.3 \%$ had the chronic obstructive pulmonary disease. Only $6.7 \%$ of patients had malignancy (table 1).

On admission to ICU, the median respiratory rate was 30 breaths/minutes, median Pao2/FiO2 was 81 (67.5130), median Sequential Organ Failure Assessment 
Table 1 Demographics and clinical characteristics of patients with COVID-19-associated pneumothorax in ICU and without pneumothorax

\begin{tabular}{|c|c|c|}
\hline & $\begin{array}{l}\text { COVID-19- } \\
\text { associated } \\
\text { pneumothorax }\end{array}$ & $\begin{array}{l}\text { COVID-19 not } \\
\text { associated } \\
\text { with } \\
\text { pneumothorax }\end{array}$ \\
\hline Baseline characteristics & $\begin{array}{l}\text { Total } \\
\mathrm{N}=75\end{array}$ & $N=1713$ \\
\hline Age $($ mean $\pm S D)$ years & $55.1( \pm 12.7)$ & NA \\
\hline Gender n (\%) & & NA \\
\hline Male & 72 (96\%) & \\
\hline Female & $3(4 \%)$ & \\
\hline Ethnicities n (\%) & & NA \\
\hline Nepalese & $14(18.7 \%)$ & \\
\hline Bangladeshi & $10(13.3 \%)$ & \\
\hline Pakistani & $9(12 \%)$ & \\
\hline Indian & $10(13.3 \%)$ & \\
\hline Filipino & $10(13.3 \%)$ & \\
\hline Qatari & $6(8 \%)$ & \\
\hline Syrian & $2(2.6 \%)$ & \\
\hline Sudani & $3(4 \%)$ & \\
\hline American & $2(2.7 \%)$ & \\
\hline Indonesian & $1(1.3 \%)$ & \\
\hline Irani & $2(2.7 \%)$ & \\
\hline Others & $6(8 \%)$ & \\
\hline Height (median IQR) cm & $\begin{array}{l}168 \text { (164 to } \\
170)\end{array}$ & NA \\
\hline Weight (median IQR) Kg & 75 (65 to 85$)$ & NA \\
\hline $\mathrm{BMI}(\mathrm{mean} \pm \mathrm{SD}) \mathrm{kg} / \mathrm{m} 2$ & $27.2( \pm 3.9)$ & NA \\
\hline Comorbidities n (\%) & & NA \\
\hline HTN & $22(29.3 \%)$ & \\
\hline T2DM & $21(28 \%)$ & \\
\hline CVA & $3(4 \%)$ & \\
\hline CAD & $3(4 \%)$ & \\
\hline COPD & $1(1.3 \%)$ & \\
\hline Asthma & $5(6.7 \%)$ & \\
\hline TB & $1(1.3 \%)$ & \\
\hline CKD & $3(4 \%)$ & \\
\hline HIV & $0(0 \%)$ & \\
\hline Malignancy & $5(6.7 \%)$ & \\
\hline \multicolumn{3}{|l|}{ Vitals at admission to ICU } \\
\hline Temperature (median IQR) & $\begin{array}{l}36.9(36.6- \\
37.8)\end{array}$ & NA \\
\hline Heart rate (mean $\pm S D$ ) bpm & $101( \pm 21.3)$ & NA \\
\hline MAP $($ mean $\pm S D) ~ m m ~ H g$ & $93.1( \pm 14.1)$ & NA \\
\hline $\begin{array}{l}\text { Respiratory rate (median } \\
\text { IQR) breaths/min }\end{array}$ & 30 (26 to 34$)$ & NA \\
\hline SOFA score (median IQR) & 2 (2 to 4$)$ & NA \\
\hline SOFA score (mean \pm SD) & $2.92( \pm 1.75)$ & $4.3( \pm 4)$ \\
\hline
\end{tabular}

Continued
Table 1 Continued

\begin{tabular}{|c|c|c|}
\hline & $\begin{array}{l}\text { COVID-19- } \\
\text { associated } \\
\text { pneumothorax }\end{array}$ & $\begin{array}{l}\text { COVID-19 not } \\
\text { associated } \\
\text { with } \\
\text { pneumothorax }\end{array}$ \\
\hline Baseline characteristics & $\begin{array}{l}\text { Total } \\
\mathrm{N}=75\end{array}$ & $N=1713$ \\
\hline $\begin{array}{l}\text { Pneumonia severity index } \\
\text { (median IQR) }\end{array}$ & 77 (65 to 96) & NA \\
\hline APACHE II score (mean \pm SD) & $8.8( \pm 2.9)$ & $13.5( \pm 6.4)$ \\
\hline $\begin{array}{l}\text { Pneumonia on chest XR } n \\
\text { (\%) }\end{array}$ & $70(93.3 \%)$ & NA \\
\hline $\begin{array}{l}\text { Inotrope use during ICU } \\
\text { stay } \mathrm{n}(\%)\end{array}$ & $73(97.3 \%)$ & NA \\
\hline
\end{tabular}

APACHE II, Acute Physiology and Chronic Health Evaluation II; $\mathrm{BMI}$, Body mass index; CAD, Coronary artery disease; COPD, Chronic obstructive pulmonary disease; CVA, Cerebrovascular accident; HTN, hypertension; ICU, intensive care unit; MAP, mean arterial pressure; MENA, Middle East and North Africa; NA, not available; SOFA, Sequential organ failure assessment; TB, Tuberculosis; T2DM, Type 2 diabetes mellitus.

(SOFA) score was 2 (2-4), mean Acute Physiology and Chronic Health Evaluation II (APACHE II) score of 8.8 $( \pm 2.9)$ and the median pneumonia severity index was 76 (65-96). All patients had abnormal chest XR findings suggestive of COVID-19 pneumonia on admission. 97.3\% of the patients required inotropic support at some point during ICU stay. All patients received intravenous antibiotics, steroids and antiviral therapy during their ICU stay (table 1).

$97.3 \%$ of patients required respiratory support before developing pneumothorax. This included supplemental oxygen, non-invasive ventilation (NIV) and invasive ventilation. Two per cent $(n=2)$ patients were on room air when they developed pneumothorax, and they were shifted to ICU after the development of pneumothorax. Thus, pneumothorax incidence in patients with COVID-19 pneumonia requiring ICU admission was calculated as $4.08 \%$ (table 2).

\section{Respiratory support}

Most patients required more than one form of respiratory support. $13.3 \%(n=10)$ were on NIV, whereas $80 \%(n=60)$ were mechanically ventilated when they developed pneumothorax (table 2).

After developing pneumothorax, all the patients required respiratory support, with $86.7 \%$ of patients requiring invasive ventilation, remaining $13.3 \%$ required different forms of respiratory support (table 3). The median pressure of arterial oxygen to fractional inspired oxygen concentration $(\mathrm{PaO} 2 / \mathrm{FiO} 2)$ before developing pneumothorax was 122 (84-179) (tables 2 and 3).

The median tidal volume (tidal volume of $6-8 \mathrm{~mL}$ per ideal body weight was used for each patient) was $400 \mathrm{~mL}$ (358-420 mL), mean plateau pressure was $26.4 \mathrm{~cm} \mathrm{H} 2 \mathrm{O}$ $( \pm 4.27 \mathrm{~cm} \mathrm{H} 2 \mathrm{O})$, median PEEP was $8 \mathrm{~cm} \mathrm{H} 2 \mathrm{O}(6-10$ 
Table 2 Respiratory support before and after developing pneumothorax

\begin{tabular}{ll}
\hline $\begin{array}{l}\text { Supplementary oxygen uses before } \\
\text { pneumothorax n (\%) }\end{array}$ & $73(97.3)$ \\
$\begin{array}{l}\text { Patient on IV who developed a pneumothorax } \\
\mathrm{n}(\%)\end{array}$ & $60(80)$ \\
$\begin{array}{l}\text { Patients on NIV who developed a } \\
\text { pneumothorax n (\%) }\end{array}$ & $10(13.3)$ \\
$\begin{array}{l}\text { Supplementary oxygen used after } \\
\text { pneumothorax N (\%) }\end{array}$ & $75(100)$ \\
$\begin{array}{l}\text { Number of patients requiring NIV after } \\
\text { developing pneumothorax N (\%) }\end{array}$ & $3(4 \%)$ \\
$\begin{array}{l}\text { Number of patients requiring IV after } \\
\text { developing pneumothorax N (\%) }\end{array}$ & $65(86.7 \%)$ \\
\hline
\end{tabular}

IV, invasive ventilation; NIV, non-invasive ventilation.

$\mathrm{cm} \mathrm{H} \mathrm{O})$ and mean driving pressure was $17.3 \mathrm{~cm} \mathrm{H} 20$ $( \pm 5.19 \mathrm{~cm} \mathrm{H} 2 \mathrm{O})$ (table 3$)$.

The median time to develop pneumothorax from ICU admission was 15 days (6-23 days) and was 21 days (13.5-32 days) from the first COVID-19 PCR. Patients who were on NIV developed pneumothorax between 3.5 and 15 days, with the median being 4 . Whereas patients on invasive ventilation developed pneumothorax between 6 and 32 days, the median was 13 days (table 3 ).

\section{Risk factors}

$45.3 \%(n=34)$ of patients had one or more procedures (known to be associated with pneumothorax) done within the preceding 24hours of the development of pneumothorax. Out of the total procedures $(n=65)$, the most commonly performed procedures were internal jugular line insertion and intubation with a frequency of $35.3 \%$ each. A detailed list of the procedures is provided in table 4.

\begin{tabular}{|c|c|}
\hline Ventilatory setting in intubated patients & $400(358-420) \mathrm{mL}$ \\
\hline before developing pneumothorax & $26.4( \pm 4.27) \mathrm{cm}$ \\
\hline TV (median IQR) & $\mathrm{H} 2 \mathrm{O}$ \\
\hline Plateau pressure (mean $\pm S D)$ & $8(6-10) \mathrm{cm} \mathrm{H} 2 \mathrm{O}$ \\
\hline PEEP (median IQR) & $17.3( \pm 5.19) \mathrm{cm}$ \\
\hline Driving pressure (mean $\pm S D$ ) & $\mathrm{H} 2 \mathrm{O}$ \\
\hline $\begin{array}{l}\text { Length NIV before developing } \\
\text { pneumothorax (median IQR) }\end{array}$ & 1 (1-2) day \\
\hline $\begin{array}{l}\text { Length of IV before developing } \\
\text { pneumothorax (median IQR) }\end{array}$ & 9 (4-21) days \\
\hline $\begin{array}{l}\mathrm{PaO} 2 / \mathrm{FiO} 2 \text { ratio on admission (median } \\
\text { IQR) }\end{array}$ & $81(67.5-130)$ \\
\hline $\begin{array}{l}\mathrm{PaO} 2 / \mathrm{FiO} 2 \text { before pneumothorax } \\
\text { (median IQR) }\end{array}$ & $122(84-179)$ \\
\hline
\end{tabular}

NIV, non-invasive ventilation; $\mathrm{PaO} 2 / \mathrm{FIO} 2$, pressure of arterial oxygen to fractional inspired oxygen concentration; PEEP, positive end-expiratory pressure; TV, tidal volume.
Table 4 Procedures preceding pneumothorax in the last 24 hours

No of patients who underwent procedures 34 (45.3) within the preceding 24 hours before developing pneumothorax $\mathrm{n}(\%)$

\begin{tabular}{lc} 
No of procedures preceding pneumothorax & 65 \\
VA ECMO & $1(1.5 \%)$ \\
\hline VV ECMO & $1(1.5 \%)$ \\
\hline NGT insertion & $11(16.2 \%)$ \\
\hline Tracheostomy & $2(3 \%)$ \\
\hline Internal jugular line insertion & $23(35.3 \%)$ \\
\hline Intubation & $23(35.3 \%)$ \\
\hline Postextubation, while on ECMO & $1(1.5 \%)$ \\
\hline Subclavian central venous line insertion & $2(3 \%)$ \\
\hline Therapeutic/diagnostic pleural tapping & $1(1.5 \%)$ \\
\hline
\end{tabular}

ECMO, extracorporeal membrane oxygenation; NGT, nasogastric tube; VA ECMO, venoarterial extracorporeal membrane oxygenation; VV ECMO, venovenous extracorporeal membrane oxygenation.

Investigations done on admission are summarised in online supplemental table A.

\section{Characteristics of the pneumothorax}

Pneumothorax occurred more on the right side $(56 \%)$ than on the left side $(28 \%)$. At the same time, pneumothorax occurred bilaterally in $16 \%$ of patients. A chest tube was inserted for $78.7 \% \%(\mathrm{n}=59)$, and others were managed conservatively. None of the patients required surgical intervention. When the chest tube was inserted, it was removed at a median of 8 days (4-18days). The recurrence rate was $9.3 \%$. The median length of ICU stay was 28 days (20.5-45.8). After developing pneumothorax, the length of mechanical ventilation ranged from 6 to 35 days, with a median of 13 days. After developing pneumothorax, the length of NIV ranged from 3.5 to 15 days, with a median of 4 days, with a length of IV ranging from 6 to 32 days, with a median of 13 days. Almost $44 \%$ of patients eventually ended up with tracheostomy. In-hospital mortality in the patients with COVID-19-related pneumothorax was $53.3 \%(\mathrm{n}=40)$ (table 5$)$.

\section{Mortality}

We compared both parametric and non-parametric variables based on mortality in patients with COVID-19-related pneumothorax requiring ICU admission. The analysis found statistically significant difference in mortality on the basis of SOFA score $(\mathrm{f}=6.32, \mathrm{p}=0.014)$, respiratory rate $(\mathrm{f}=7.26, \mathrm{p}=0.008)$, PEEP $(\mathrm{f}=5.234, \mathrm{p}=0.027)$, D-Dimer $(\mathrm{f}=4.1, \mathrm{p}=0.049)$, fibrinogen $(\mathrm{f}=5.358, \mathrm{p}=0.023)$, blood urea nitrogen $(\mathrm{f}=5.714, \mathrm{p}=0.020)$, developing pneumothorax while on invasive ventilation $(\mathrm{f}=5.2857$, $\mathrm{p}=0.022$ ), need for invasive ventilation after developing pneumothorax $(\mathrm{f}=13.01, \mathrm{p} \leq 0.001)$, use of vasopressor/ inotropes during ICU stay $(\mathrm{f}=8.5893, \mathrm{p}=0.003)$ and when 
Table 5 Treatment, the outcome of COVID-19-associated pneumothorax and outcome of patients with COVID-19 without pneumothorax

\begin{tabular}{|c|c|c|}
\hline Outcome/treatment & $\begin{array}{l}\text { COVID-19-associated } \\
\text { pneumothorax }\end{array}$ & $\begin{array}{l}\text { COVID-19 not associated } \\
\text { with pneumothorax }\end{array}$ \\
\hline Side of pneumothorax $\mathrm{N}(\%)$ & & NA \\
\hline Bilateral & $12(16)$ & \\
\hline Left & $21(28)$ & \\
\hline Right & $42(56)$ & \\
\hline Chest tube insertion $\mathrm{n}(\%)$ & $59(78.7)$ & NA \\
\hline Duration of a chest tube (median IQR) & $8(4-18)$ & NA \\
\hline Recurrences n (\%) & $7(9.3)$ & NA \\
\hline \multicolumn{3}{|l|}{ Length of ICU stay (days) } \\
\hline (Median + IQR) & 28 (20.5-45.8) days & $14( \pm 20.5)$ days \\
\hline$($ Mean $\pm S D)$ & $39.2( \pm 32.9)$ days & \\
\hline Length of NIV after developing pneumothorax (days) (median IQR) & $4(3.5-15)$ days & NA \\
\hline Length of IV after developing pneumothorax (median IQR) & $13(6-32)$ days & NA \\
\hline Need for tracheostomy n (\%) & $33(44 \%)$ & NA \\
\hline No of days in ICU before developing pneumothorax (median IQR) & 15 (6-23) days & NA \\
\hline $\begin{array}{l}\text { Time elapsed from first COVID-19 PCR to development of } \\
\text { pneumothorax (days) (median IQR) }\end{array}$ & 21 (13.5-32) days & NA \\
\hline Time to negative COVID-19 PCR (days) (median IQR) & $\begin{array}{l}28 \text { (24-42) days } \\
\text { (maximum 138) }\end{array}$ & NA \\
\hline In-hospital mortality n (\%) & $40(53.3)$ & $236(13.1)$ \\
\hline
\end{tabular}

ICU, intensive care unit; IV, invasive ventilation; NA, not available; NIV, non-invasive ventilation.

procedures known to cause pneumothorax were being performed within 24 hours preceding development of pneumothorax (online supplemental tables B and C).

\section{Outcome parameters of the patient with critically ill COVID-19} patients without pneumothorax

Although our study is primarily not a comparative study, some of the outcome parameters for the critically ill COVID-19 patients who did not develop pneumothorax were calculated to compare and better understand the association. For the patients who were admitted to ICU with COVID-19 and did not develop a pneumothorax, the mean SOFA score was $4.3( \pm 4)$, APACHE II score 13.5 $( \pm 6.4)$, mean length of ICU stay was 14 days ( \pm 20.5 days) and in-hospital mortality was $13.1 \%(\mathrm{n}=236)$ (tables 1 and $5)$.

\section{DISCUSSION}

COVID-19 is a multiorgan disease, but respiratory involvement is the most common in severe disease. Any phenomenon that strains the respiratory system further can contribute to morbidity and mortality. Pneumothorax is a source of morbidity and mortality. This is an extensive retrospective study on COVID-19-associated pneumothorax in critically ill patients and one of the few studies with a sizeable cohort from the MENA region.
In our study, pneumothorax occurred in $4.2 \%$ of the critically ill COVID-19 patients. As 2.6\% ( $\mathrm{n}=2)$ patients were on room air when they developed pneumothorax and were shifted to ICU after developing pneumothorax. Therefore, the incidence rate of COVID-19-related pneumothorax was calculated as $4.08 \%$, higher than some studies but similar to a study by Marciniak et al. ${ }^{3-6} 10$

Most of the patients were male, similar to other studies. ${ }^{6}$ Our population had diverse nationalities.

Most of our patient population was previously healthy. The mean SOFA score of COVID-19 patients who developed pneumothorax was $2.92( \pm 1.75)$ compared with a mean of $4.3( \pm 4)$ in COVID-19 patients without pneumothorax (table 1). Whereas, the mean APACHE II score of $8.8( \pm 2.9)$ in patients with pneumothorax compared with the mean APACHE II score of $13.5( \pm 6.4)$ in patients without pneumothorax (table 1). This indicates that patients with COVID-19 can develop pneumothorax even in the presence of lower estimated mortality and even without evidence of multiorgan failure on ICU admission. However, the mortality of patients who developed pneumothorax was higher than the comparison group.

All patients had abnormal chest XR findings, most of them having bilateral ground glass shadows on admission to ICU. Most of the patients were on some form of respiratory support when they developed pneumothorax. The ventilatory setting was not available for all patients. 
However, the available data review indicates that other lung-protective ventilation strategies were not violated except the slightly higher driving pressure $(17.3 \mathrm{~cm} \mathrm{H} 20$ $( \pm 5.19 \mathrm{~cm} \mathrm{H} 2 \mathrm{O})$. This indicates that the risk of barotrauma in these patients is high even when lung-protective strategies were being applied while positively ventilating the patients. Multiple mechanisms can contribute to it, such as cyst formation due to barotrauma or as a late consequence of ARDS may play an important role. ${ }^{67}$ Authors postulate that the elevated driving pressure may cause increased shear pressure on the alveolar wall, leading to barotrauma. ${ }^{10}$ The exact mechanism is still unclear and needs further investigation. There was also a statistically significant difference in mortality based on PEEP.

Procedures that are known to cause pneumothorax preceded $45.3 \%$ of the events within 24 hours of the event. Most of the pneumothorax occurred on the right side after right internal venous catheter insertion. This high number of possibly iatrogenic pneumothorax may reflect the poor performance under stressful conditions or limited operator expertise, given the pandemic's overwhelmed situation.

The neutrophil/lymphocyte ratio was found to be high in these patients indicating high physiological stress. Mean fibrinogen and median interleukin- 6 were also elevated, most likely due to activation of the coagulation cascade and cytokine storm (online supplemental table A). Further studies are needed to determine the association of this phenomenon with the development of pneumothorax.

A chest tube was inserted for most patients to manage pneumothorax, as seen in previous studies. ${ }^{10}$ We demonstrated that in patients with COVID-19-associated pneumothorax requiring chest tube placement was not associated with higher mortality.

Almost $9.3 \%$ of the patients developed recurrent episodes, with one patient developing as many as four distinct episodes during ICU stay.

Median stay in ICU for all COVID-19 patients was reported as 5 days (2-9) by Rees $e t$ al. ${ }^{12}$ Our study showed a longer median length of stay of 28 days (20.5-45.8) for critically ill patients with COVID-19-related pneumothorax. Compared with patients without pneumothorax, ICU stay was longer in patients who developed a pneumothorax (mean of $39.2 \pm 32.9$ days vs mean of $14 \pm 20.5$ days) (table 5). This reflects a prolonged ICU stay due to COVID-19-related pneumothorax. It may also indicate that patients with COVID-19 pneumonia are more prone to develop pneumothorax with prolonged ICU admission.

All patients required respiratory support after developing pneumothorax. The tracheostomy rate was $44 \%$ compared with $29.72 \%$ in overall COVID-19 patients requiring ICU admission, as reported by Sancho et al. ${ }^{13}$

In-hospital mortality in the patients with COVID-19related pneumothorax was $53.3 \%$. The mortality rate in patients with COVID-19 pneumonia requiring ICU who did not develop pneumothorax was calculated as $13 \%$ $(\mathrm{n}=236) \quad$ (table 5). The odds of mortality in patients with COVID-19 pneumonia with pneumothorax are 7.15 (95\% CI 4.4 to $11.4, \mathrm{p}<0.0001$ ) compared with those who did not develop pneumothorax. This indicates pneumothorax as a potential independent risk factor associated with mortality in patients with COVID-19 pneumonia requiring ICU admission.

This study indicates that the pneumothorax rate is higher in-patient requiring ICU admission, with associated higher mortality and prolonged hospital stay.

Our study does have some limitations. The limitations of our study stem from the study design being retrospective and observational study. Despite an extensive review, there was some missing information when screening for risk factors of pneumothorax.

Pneumothorax is a well-recognised complication of COVID-19 in critically ill patients, and it is related to poor prognosis. Therefore, all possible efforts should be made towards prevention and prompt recognition. The patient that is at risk includes male, those of southeast Asian origin, with abnormal chest XR findings on admission, those requiring respiratory support on admission, mechanically ventilated, prolonged ICU admission, those with high neutrophil/lymphocyte ratio, high CRP with evidence of cytokine storm and those undergoing procedures that may cause pneumothorax.

Wang et al demonstrated that protective ventilation strategies, neuromuscular blockers, timely extracorporeal membrane oxygenation or extracorporeal carbon dioxide removal combined with ultraprotective ventilation might play an essential role in the prevention of pneumothorax in critically ill patients with severe ARDS. ${ }^{11}$

\section{INTERPRETATION/CONCLUSION}

Pneumothorax is a common complication in patients with COVID-19 requiring ICU admission. It is associated with poor prognosis and outcome. Prevention, early recognition and prompt treatment may improve survival.

Contributors JA: principal investigator, conceptualisation, methodology, literature review, data collection and interpretation, manuscript writing. ZY: literature review, methodology, conceptualisation, data analysis and interpretation, manuscript writing and critical review. YA and MIAA: literature review and data collection. ASSI: data retrieval. NK: critical review, revisions in the manuscript and guaranter of the study. All authors: review and approval of the final manuscript.

Funding Funding for publications costs is covered by Hamad Medical Corporation. The Grant number for the funder is not applicable.

Competing interests None declared.

Patient consent for publication Not applicable.

Ethics approval This work is original, has not been and is not considered for publication in any other Journal. All authors have reviewed and approved the final version of the manuscript. The study was approved by the Medical Research Centre (MRC) Qatar. (MRC-01-20-1116)

Provenance and peer review Not commissioned; externally peer reviewed.

Data availability statement Data are available on reasonable request. The data that support the findings of this study are available from the corresponding author on reasonable request.

Supplemental material This content has been supplied by the author(s). It has not been vetted by BMJ Publishing Group Limited (BMJ) and may not have been 
peer-reviewed. Any opinions or recommendations discussed are solely those of the author(s) and are not endorsed by BMJ. BMJ disclaims all liability and responsibility arising from any reliance placed on the content. Where the content includes any translated material, BMJ does not warrant the accuracy and reliability of the translations (including but not limited to local regulations, clinical guidelines, terminology, drug names and drug dosages), and is not responsible for any error and/or omissions arising from translation and adaptation or otherwise.

Open access This is an open access article distributed in accordance with the Creative Commons Attribution Non Commercial (CC BY-NC 4.0) license, which permits others to distribute, remix, adapt, build upon this work non-commercially, and license their derivative works on different terms, provided the original work is properly cited, appropriate credit is given, any changes made indicated, and the use is non-commercial. See: http://creativecommons.org/licenses/by-nc/4.0/.

\section{ORCID iDs}

Jaweria Akram http://orcid.org/0000-0003-4487-014X

Zohaib Yousaf http://orcid.org/0000-0002-4631-9899

Yasir Alabbas http://orcid.org/0000-0003-0039-7565

\section{REFERENCES}

1 Deshmukh V, Motwani R, Kumar A, et al. Histopathological observations in COVID-19: a systematic review. J Clin Pathol 2021;74:76-83.

2 Iba T, Connors JM, Levy JH. The coagulopathy, endotheliopathy, and vasculitis of COVID-19. Inflamm Res 2020;69:1181-9.

3 Chen N, Zhou M, Dong X, et al. Epidemiological and clinical characteristics of 99 cases of 2019 novel coronavirus pneumonia in Wuhan, China: a descriptive study. Lancet 2020;395:507-13.
4 Yang X, Yu Y, Xu J, et al. Clinical course and outcomes of critically ill patients with SARS-CoV-2 pneumonia in Wuhan, China: a singlecentered, retrospective, observational study. Lancet Respir Med 2020;8:475-81.

5 Yang F, Shi S, Zhu J. Analysis of 92 deceased patients with COVID-19. J Med Virol 2020.

6 Martinelli AW, Ingle T, Newman J, et al. COVID-19 and pneumothorax: a multicentre retrospective case series. Eur Respir J 2020;56:2002697. doi:10.1183/13993003.02697-2020

7 McGuinness G, Zhan C, Rosenberg N, et al. Increased incidence of barotrauma in patients with COVID-19 on invasive mechanical ventilation. Radiology 2020;297:E252-62. doi:10.1148/ radiol.2020202352

8 Abate SM, Ahmed Ali S, Mantfardo B, et al. Rate of intensive care unit admission and outcomes among patients with coronavirus: a systematic review and meta-analysis. PLoS One 2020;15:e0235653.

9 Zantah M, Dominguez Castillo E, Townsend R, et al. Pneumothorax in COVID-19 disease- incidence and clinical characteristics. Respir Res 2020;21.

10 Marciniak SJ, Farrell J, Rostron A, et al. COVID-19 pneumothorax in the UK: a prospective observational study using the ISARIC who clinical characterisation protocol. Eur Respir J 2021;58:2100929.

11 Wang X-H, Duan J, Han X, et al. High incidence and mortality of pneumothorax in critically ill patients with COVID-19. Heart Lung 2021;50:37-43.

12 Rees EM, Nightingale ES, Jafari Y, et al. COVID-19 length of hospital stay: a systematic review and data synthesis. BMC Med 2020;18:270.

13 Sancho J, Ferrer S, Lahosa C, et al. Tracheostomy in patients with COVID-19: predictors and clinical features. Eur Arch Otorhinolaryngol 2021;278:3911-9. 